\title{
Approval of chronic medication - Discovery Health hits new lows
}

To the Editor: I was asked to see a patient with poorly controlled hypertension and a strong family history of type 2 diabetes. In June 2010, glucometer readings were consistently raised (approximately $18 \mathrm{mmol} / \mathrm{l}$ ) and his general practitioner did an $\mathrm{HBA}_{1} \mathrm{C}$, which was markedly elevated at 10.9. A diagnosis of type 2 diabetes was made and he was commenced on metformin. A fasting lipogram showed significant dyslipidaemia consistent with metabolic syndrome.

After adjusting his antihypertensive treatment, I completed his chronic medication forms, which included metformin. I received a faxed reply from Dr Andrew Murray saying that his $\mathrm{HBA}_{1} \mathrm{C}$ was not considered diagnostic for type 2 diabetes, and benefits for metformin were denied because there was no documented laboratory glucose. I wrote to Dr Errol Gottlich, who has helped me in the past with this type of issue. I pointed out that the American Diabetes Association now considers $\mathrm{HBA}_{1} \mathrm{C}$ a diagnostic test for diabetes $\left(\mathrm{HBA}_{1} \mathrm{C}>6.5\right)$ and, furthermore, with a level of 10.9 , there was no alternative diagnosis.

I learnt from Dr Gottlich that Dr Murray was in China, and he would forward my email to the relevant department. Dr Ndlovu telephoned and still refused to approve metformin, based on the fact that I had not proved the diagnosis because Discovery did not recognise $\mathrm{HBA}_{1} \mathrm{C}$ as a diagnostic test. I again explained that, as a professor of medicine, I could surely make a diagnosis of type 2 diabetes and understood the diagnostic criteria, but he still refused to back down.

I am sure many readers are familiar with this sort of situation and have similar frustrations. I was personally insulted by the arrogance of the advisor. I am intelligent enough to understand there is a need for medical aids to ensure that the diagnosis of type 2 diabetes is established correctly to avoid over-servicing but, when discussing an individual patient with a very senior academic and colleague, you would think that the advisor would use his discretion instead of following a mindless bureaucratic protocol.

Fortunately this patient can afford to continue his metformin out of his own pocket for the time being, but many patients do not have the resources to do this and suffer the consequences of uncontrolled diabetes.

\section{Brian Rayner}

Division of Hypertension and Nephrology

Department of Medicine

University of Cape Town

brian.rayner@uct.ac.za 